\title{
The Importance of Teachers' Universal Design for Transition Principles Knowledge in Preparing Students Who Are Deaf and Hard of Hearing for the Life after School in Saudi Arabia
}

\author{
Marzouq Ali Alzahrani1,2 \\ ${ }^{1}$ Concordia University, Chicago, USA \\ ${ }^{2}$ King Saud University, Riyadh, KSA \\ Email:maz1385@hotmail.com
}

How to cite this paper: Alzahrani, M. A. (2018). The Importance of Teachers' Universal Design for Transition Principles Knowledge in Preparing Students Who Are Deaf and Hard of Hearing for the Life after School in Saudi Arabia. Creative Education, 9, 513-534.

https://doi.org/10.4236/ce.2018.93036

Received: February 12, 2018

Accepted: March 27, 2018

Published: March 30, 2018

Copyright $\odot 2018$ by author and Scientific Research Publishing Inc. This work is licensed under the Creative Commons Attribution International License (CC BY 4.0).

http://creativecommons.org/licenses/by/4.0/

\begin{abstract}
This research sought to establish the importance of teachers' UDT knowledge in preparing students who are deaf and hard of hearing $(\mathrm{DH} / \mathrm{H})$. The study targeted $\mathrm{DH} / \mathrm{H}$ in general schools in KSA. The main objective of the study was to examine whether the concepts of UDT are understood and successfully incorporated into the activities of teachers, who teach Deaf and Hard of Hearing students in general education schools of Saudi Arabian educational system. The paper relied on both secondary and primary data. It sampled some teachers in general schools who teach both normal and Deaf and Hard of Hearing students. The research used interviews as the main tool for collecting primary data while secondary data were achieved from previous works by scholars. The paper targeted schools in Riyadh City in Saudi Arabia. The findings of this research will aid educational policymakers in striking a balance in the education system between normal students and those living with disabilities. The findings of this research indicate the teachers are not well equipped with skills in UDT principles hence the need to prepare seminars and in-service training programs to train the teachers and at the same time incorporate UDT programs in teachers' training courses.
\end{abstract}

\section{Keywords}

Students Living with a Disability, UDT Principles, Deaf and Hard of Hearing Students, Educational System, Transition

\section{Introduction}

Educational system in KSA has worked on educate students with disabilities in 
an integrated framework, since a decade (Hadidi \& Al Khateeb, 2015). Integration or transition was a challenging task, but many gaps were in.

Main point is focused on academics without ignoring the students' transitional needs (Al-Zahrani, 2012). So, programs of special education have been evolved in Saudi Arabia for years, to increase, refine, and support the educational attainment for students with disabilities (Aldabas, 2015). Universal Design for Learning (UDL) framework has been used as a global vision for the integration of students with disabilities. it had been included instruction curriculum designs, academic transition planning, and student assessments to fill the gaps in general school, to achieve successful transitions of students to inclusive educational programs (Mapolisa \& Tshabalala, 2013), but students with disabilities often got straight less results than their peers, according to results obtained with Kim \& Lee (2016). Unfortunately, systems like "UDL" and "UDT" models have been adopted for several years in western countries such as the United States, while, it is considered new features in KSA.

Few researches discussed this topic, as a direct result, there is a lack of awareness of UDT, poor implementation of transition, and lack of transition curricula for $\mathrm{D} / \mathrm{HH}$ in the KSA. Therefore, the current literature Stresses needs in field of transition generally, and the in sections of UDT and $\mathrm{D} / \mathrm{HH}$, specifically, in the KSA. It will make a hug differences if UDT implements in this schools, which improves them real-life skills (Hartmann \&Weismer, 2016).

Special education programs in KSA have evolved over recent years, increasing the number of schools whose objectives are to support the educational attainment for students with disabilities (Aldabas, 2015). D/HH has been missed advocacy for training, preparing for employ ability, training for future life, preparing for higher education which observance their disabilities and academic needs; thus, there is urgently needed UDT programs to be introduced to Saudi Arabian schools, just in case if transition planning and implementation improved, students with disabilities would benefit from UDT-universal transition model approach.

It is an attempt to investigate the implementation of UDT in the existing programs of transition regarding the KSA, and comparing results in KSA as in USA. Focus will be on the barriers or difficulties that facing UDT implementation in the programs of transition education in KSA, and barriers which lead to lack of understanding by teachers of UDT concepts might have on the future implementation transition programs.

In the end, I hope that this study will contribute to stimulate further research in this area, and provides an outline to assist decision makers to adopt.

\section{Research Questions}

The purpose of this study is to examine whether the concepts of UDT are understood and successfully incorporated into the activities of teachers, who teach Deaf and Hard of Hearing $(\mathrm{DH} / \mathrm{H})$ students in general and special education 
schools of Saudi Arabian educational system. Therefore, the following questions were based on the relationship between teachers' understanding of the seven principles of UDT and the barriers that might occur when UDT as an instructional design framework is implemented in the schools of KSA:

1) What do teachers know about UDT?

2) What are the barriers to implementing UDT in Saudi schools?

3) How does the overall teachers' understanding of UDT principles affect UDT programs in general and special education schools?

\section{Review of Literature}

Educational Backgrounds for Special Needs Learners:

The education ministry of KSA at 1962 created "Department of Special Education" by Resolution No. 674/36/40 of Saudi Arabia laws, programs which were established for students getting special education:

a) Boarding schools and facilities were been built for learners who have hosted at the institutes for five days, today, students travel to Institutes daily to get education in special institutes.

b) Until 1996-1997 there only 67 programs existed seeking to teach 9424 special needs students, by 2000, increased students to 13,914 educated into the 226 curriculums, around of Saudi Arabia, which have been enlarged quickly to around 2577 programs all over the nation (Al-Mousa, 2008)

\subsection{Evolution of Transition Services for Deaf and Hard of Hearing Students}

Until the second half of the 20th century, special needs programs for disabled youth in Saudi Arabia only focused on blind students and programs, which introduced Braille into the learning environments at the prompting of Ahmad Aba Hessain (Aldabas, 2015; Bin Battal, 2016). The significant change did not come until 1964 when the Saudi Ministry of Education Administration of Special Education opened the Al-Amal Institutes, the first special primary schools for deaf students using Arabic sign language tools in Riyadh. Inclusion for deaf and hearing-impaired students in Saudi Arabia evolved to separate classrooms that were constructed as amendments to the existing schools (Shaira, 2013).

Recently, Special education disciplines have been the focus of educational authorities through providing assistive educational technologies, grants, scholarships, equipment, and transportation. The General Administration of Special Education has also collaborated to plan for special education transitions in the mainstream schools for both urban and rural demographics (Bin Battal, 2016). The disabled student education services expanded with the addition of the Special Education Agency in the Saudi Arabian Ministry of Education (Aldabas, 2015). Between 1991 and 1992, 23 institutes for deaf students were open in Saudi Arabia with approximately 2855 students and 476 teachers (Bin Battal, 2016). Special disability accommodations that may be accessed in educational settings 
have evolved as critical components of planning and implementation for special needs education (Alnahdi, 2014).

The deaf and hard of hearing language learners have become "the fastest-growing subset of deaf and hearing-impaired student populations" (Cannon, Guardino, Antia, \& Luckner, 2016: p. 450). Bin Battal (2016) attributes a significant percentage of the accelerated progress for disabled student learning accommodations to the dramatic Saudi Arabian modernization and economic prosperity of the past few decades. However, the integration of students with hearing impairments with mainstream students remains challenged by deficiencies in education administration, training, and delivery. For example, Al-Zawei, Serenelli, and Lundqvist (2016) view subsequent policies for integration and transition as hindered by challenges and policies that widen the gaps in learner abilities. Aldabas (2015) concluded that Saudi Arabia must implement more professional development modules for all of the school staffs before the implementation of inclusive programs for disabled students.

\section{The Deaf and Special Education Development in Saudi Arabia}

Government aim to train all residents has been created based on international rights and religious beliefs, according to United Nations Universal Declaration of Human Rights, established in 1948. The Education ministry has therefore attempted to improve and expand the education division by comprising of producing precise strategies for teaching of students with special educational requirements. The early phases of the special educational have been begun in 1956 through discrete initiatives (Al-Mousa, 2008). 1964 started with only around 11 educators of deaf in Special education in Saudi Arabia; The Saudi government launched a program in collaboration with the UNESCO body to train and prepare 40 teachers to educate the deaf students in 1968 (Al-Muscat, 1984).

Up until the year 2002, there existed only 2 Universities in charge of training teachers who teaching to the special needs students in Saudi Arabia. Consequently, there was huge demand for launching such sectors to educate and qualify educators for special needs students. Lately, number of graduate who work with the deaf students has grown. Now, law requires tutors who teach to special needs students must have Bachelor's Degree in Special Education Needs, (Al-Musa, 1999).

\section{Inclusion and the Deaf Education}

Some D/HH learners spent day in institutes for deaf. Other students got them education in self-contained classroom in general schools. However, numerous deaf or hard of hearing learners are contained within in general education class. According to the survey carried out by Gallaudet's Annual Survey of Deaf and Hard of Hearing Children and Youth, about 51.1 percent of learners with the hearing loss get their education in a common setting with other peers (Gallaudet Research Institute, 2013). The deaf students in US get them education training by general educator. Furthermore, it is these learners usually; get them services from the itinerant educator of deaf. In some cases, itinerant educator only plays 
the role of consultant or expert, who advices and guides general educator. (Luckner \&Ayantoze, 2013 p. 415)

\section{Duties of General Education Tutor}

General educator faces numerous duties in respect to teach deaf and hard hearing students'. These tasks range from assisting with individual needs of the learners, using alternative approaches of learning and instruction, to efficiently use educational linguist, and tracking the academic progress of the students (Antia, 1999). In research carried out by Eriks-Brophy, and Whittingham (2013) which examined the enablers and the barriers to inclusion of learners with the hearing loss, contributors who had an average age of 19.7, specified that they at times had problems obtaining assistance from their tutors to give needed accommodations. Lawfully, the tutor is called for to create the compulsory accommodations for $\mathrm{D} / \mathrm{HH}$ learner, even if it has problematic.

\section{Positive Attitudes towards deaf students Inclusion}

As consequence of the incidence of learners with hearing challenges being encompassed in general education class, class teachers have presumed the accountability of being primary teacher of numerous special needs children. There exist many conflicting research concerning attitudes of the general education educators towards inclusion of special needs children, and more precisely an inclusion of learners hearing problems.

In case research of $2 \mathrm{D} / \mathrm{HH}$ learners included in a secondary school in Netherlands, the scholars Vermeulen, Denessen, and Knoors (2012) established that many class tutors had a positive attitude on inclusion of learners with a hearing loss, particularly if the learners behaved well and showed academicals efforts of succeeding.

\section{Negative Attitude towards the Inclusion}

As beforehand mentioned in respect to the positive attitudes, scholars have reported contradictory outcomes on whether the general education tutors have a negative attitude on inclusion. A study by Eriks-Brophy and Whittingham (2013) categorized general education tutors with a negative attitude on inclusion as "uncompromising in their training and evaluation approaches" and "reluctant to keep communication with the parents and ask for their participation in educational progress" (p. 66). The researchers indicated this major reason why some teachers can develop a negative attitude towards inclusion.

\section{The effect of Teaching on Meeting Needs of the D/HH Learners}

One typical cause of the negative attitude towards inclusion of learners with hearing problem is a sense of unpreparedness. There were studies in which investigators found that big number of educators had positive attitude on inclusion, however many teachers still shown that teachers still felt unprepared for this task. General education tutors reported that they sensed that their educator preparation courses did not communicate implications of the hearing loss problems on learning, or skills needed to educate learners with hearing loss problems (Eriks-Brophy \&Whittingham, 2013). 


\section{Expectations for Learner Performance}

Tutor expectations are vital for the efficiency of the inclusion. Scholars have identified that tutors are more expected to have a lower expectancy for learners with disable learners than for learners without any disabilities, and teachers less expected to uphold responsibility for learners who are disable than for the non-disabled peers (Cook, 2004). Nevertheless, in the research by Luckier and Muir carried out in western U.S state, researchers established that high hopes were a recurrent factor in effectively included learners (Luckner \& Sebald 2013). The high expectations are vital in education of the $\mathrm{D} / \mathrm{HH}$ learners because they inspire students to endeavor to attain their full goals.

\section{Professional Development and training}

With respects to the professional familiarity and training of the teachers, there is sufficient proof in literature works which support the concept that training either in-service or pre-service or is a significant factor in enhancing inclusive educational practices. The social constructivist viewpoint on the school teachers and principals' attitudes unavoidably acknowledges that their morals and supplementing knowledge effect their actions in execution of the inclusive education plans. For instance, Carrington et al. (2010) claimed that schools' workforces' attitudes, effectiveness and values are disturbing the growing organizational paradigm known as inclusive education. Furthermore, Avramidis and Kalyva (2017: p. 139) claimed that numerous teachers and principals are lacking in the professional education on inclusive education therefore resulting in challenges in incorporating these learners in general schools.

\subsection{Universal Designs for Transition and Learning}

A few studies that were conducted on this new framework found that the combined use of UDT and UDL frameworks can effectively address the needs of the vast majority of students, including deaf and hard of hearing students. However, teachers need continuing education about this relatively new concept to close any gap between evidence and perception, which may lead to a failure to implement UDT. An evidence-based framework will impact students, teachers, and parents alike. It will provide a coherent framework to teach and prepare all learners with their different needs including deaf and hard of hearing students to their after-school life.

Educational faculties, researchers, and national legislators have collectively investigated the development of frameworks and instructional models that may explain how to provide all students with the opportunity to learn (Wehmeyer, 2006; Aslaksen et al., 1997). The universal design expands the education infrastructures, educational materials and support resources, and learning facilities to accommodate the "widest range of student demographics" (Rose, Harbour, Johnston, Daley, \& Abarbnell, 2006: p. 1). Further, the concept of universal design encompasses the pursuit of specialized solutions that are necessary for student diversity without stigmatizing a particular student demographic (Aslaksen, 
Bergh, Bringa, \& Heggem, 1997).

\subsection{Seven Principles of Universal Design for Transition}

According to the National Center on Universal Design for Learning (2010), UDT is a set of principles of flexibility for the presentation of information, student responses to knowledge, and the student engagement levels in learning. The seven UDT principles include 1) Equitable Utility; 2) Flexibility of Utility; 3) Simplistic and Intuitive Utility; 4) Perceptiveness of Information; 5) Tolerance for Error; 6) Low Physical Effort; 7) Size and Space for Approach and Use (Aslaksen et al., 1997).

Compared to the UDL framework, on which UDT was based, the UDT design is simple and intuitive, and it is comprehensible by users with a diversity of language, skill and experience backgrounds (Scott et al., 2011). Perceptible information addresses the degree to which the design communicates needful information in a manner that is unaffected by conditions and sensory abilities. Tolerance for error increases the capacity to minimize adverse or hazardous outcomes. Also, this design demands low physical effort, and it increases efficiency with minimal actions. The size and space of its methodology and applications make it most ideal for the user.

Besides, UDT inherits a lot of its principles from UDL, which makes it rooted in the literature of UDL integration. Evans et al. (2010) addressed the integration of UDL multiple means of engagement, expression, and representation in instructional planning training, classroom management, and strategies for assessing the student. The authors found that the approach adopted is an encouragement for disabled student success, particularly in rural demographics. Ankeny, Wilkins and Spain (2009) argued that parents must play pivotal roles in the education of their special needs children. Therefore, parents require additional transitioning program support from the instructors in the form of information sharing and resource referrals. Overall, the provisions for deaf and hearing-impaired student transitions from public general school programs to achieve success and productive adult living have been rated as insufficient and in need of further research (Luft \& Huff, 2011).

The concept of Universal Design for Transition (UDT) is a newer framework that applies the foundational concepts of Universal Design (an equitable and accessible physical environment). The concept also has a Universal Design for Learning (an equitable and accessible learning environment) or Universally Designed Instruction (equitable and accessible instruction) that is specific to the areas of Special Education Transition and Transition Planning. In the U.S., UDL, UDI, and UD principles are acknowledged as important foundational structures for education and environment. These concepts are not often celebrated or well-embraced upfront during planning; often these types of inclusive design are afterthoughts in education and are addressed as reactive efforts, such as adding accommodations later rather than planning for all initially (Stolz, 2010). The 
Kingdom of Saudi Arabia (KSA) has adopted, almost verbatim, the IDEA law for learners with disabilities.

The number of children with disabilities in general education has increased dramatically since the enactment of the Individuals with Disabilities Education Act (IDEA) of 2004 in the United States (Al-Rayes \& Al-Zahrani, 2015). According to Aud et al. (2013), approximately 95 percent of students with disabilities are receiving some services in the U.S. general education classroom. The increase in the number of students with disabilities in general education classrooms has led to a decline in separate settings for these students. Presently, only $3 \%$ of children with disabilities aged between $6-21$ years are registered in separate schools (Aud et al., 2013). Similarly, in Saudi Arabia, the perspective of inclusion has attracted further attention in the last few years. This attention has increased the numbers of deaf and hard of hearing $(\mathrm{DH} / \mathrm{H})$ students who are included in general classrooms. Furthermore, it has rapidly augmented the total number of special education curricula in general, raising the number of special education programs in schools from only 12 in 1994-1995 to 1,875 in 2004-2005 (Al-Mousa, 2008). With this amount of growth in specialized programming in general education schools with an emphasis on inclusion, there is an urgent need to review the existing literature and investigate gaps in the research.

Failure to meet adult life requirements can be a result of difficulties during transition periods because transition services for students with disabilities are either too broadly or too narrowly focused on facilitating a smooth transfer. Meanwhile, students who are $\mathrm{DH} / \mathrm{H}$ are no exception to such failures because they are part of the educational system of the country with a lack of specific planning and implementation regarding preparation for adult life via transition instruction before graduation.

According to Best, Scott, and Thoma (2015), U.S. teachers found difficulties in meeting transition-related students' needs for education because many more students with disabilities attend general education classes. For this reason, Thoma, Bartholomew, and Scott (2009) created a new framework for educational planning, instructional design, and assessment: Universal Design for Transition (UDT). UDT is an idea of instructional structure that ensures a successful transition for students with disabilities that can be applied to the U.S. and KSA. This approach adopts a number of strategies and principles primarily from UDL, to aid students with disabilities achieve their vocational, social, and above all academic objectives in their walk from school going age into adulthood (Thoma, Bartholomew, \& Scott, 2016). UDL includes knowledge and skills for educators to design their environment and instruction inclusively with foresight and purposeful planning, in contrast to a lack of planning for all and thus reacting. These UDL areas include:

(a) Multiple means of representation (which give students various ways to acquire knowledge);

(b) Expression (providing students with alternative ways of demonstrating 
what they already know);

(c) engagement (which focuses on students' interests to motivate them). UDT adds;

(d) multiple transition domains;

(e) numerous transition assessments;

(f) self-determination;

(g) multiple resources/participants.

By combining forms of assessment, giving students a variety of resources/ perspectives, and promoting student self-determination to support academic progress, a clearer potential for a successful transition to life after leaving school is apparent (Thoma et al., 2016).

UDT refers to a transparent approach to instructional planning, delivery, and assessment that bridges the gap between academic and vocational services for students with disabilities. Teachers are responsible for not only instruction in post-secondary education, but also for preparing students to meet their academic and transitional goals (Thoma et al., 2016). It is very important to design programs that cater to the needs of all students, including students with different disabilities, such as those who are $\mathrm{DH} / \mathrm{H}$ because the built environment and the social environment are not traditionally designed for them.

\subsection{The Role of Understanding UDT Principles in Improving Teachers' Performance}

Cawthon et al. (2014) specified that before teachers can apply UDT principles, they naturally should gain knowledge to identify them. Unfortunately, due to lack of professional development programs, many teachers do not own the experience, awareness, or skills to work on transitioning students with disabilities in school and then into life in general. Scott et al. (2011) concluded that the UDT strategies are effective and evidence-based supplements to traditional teaching, engagement, and assessment strategies for special education.

In the same context, Mayer (2008) argued that instructional practice should be based upon learning models that are based upon theoretically grounded empirical evidence to arrive at causal claims regarding the effectiveness of the instructional approach. To realize program success, the teachers must fully understand the principles of UDT. The disabilities literature contains extensive background in the areas of teacher preparation, transition planning and professional development for special needs instructors and conclusively calls for more evidence-based research (Fowler et al., 2014; Scott et al., 2011). In the context of Saudi Arabian schools, a study by Aldabas (2015) suggested intensive instructor training and national special education policies.

The study concluded that it is a must that Saudi Arabia adopts more professional development modules for all school staff prior to the implementation of inclusive programs for students with disabilities. 


\section{Methods}

\subsection{Design of the Study}

This research study utilizes a qualitative design. A qualitative design is appropriate for educational research contexts because it can help collect direct data from participants and reach in-depth information (Agency for Healthcare Research and Quality, 2013). The researcher settled for general education schools since you can do a comparative observational analysis between the disabled students and normal students. This research investigates Saudi Arabia's teachers' knowledge of UDT principles. The study, therefore, investigates teachers' understanding of UDT principles and the relationship between teachers' beliefs that they understand the seven principles of UDT. How does the overall teachers' understanding of UDT principles might affect UDT programs in general education schools of Saudi Arabian teachers who teach students with disabilities in general education schools in the area of Riyadh City?

This study utilized two instruments (i.e. interviews and document analysis) during an inclusion program. A case study design would be feasible because it would allow the researcher obtain in-depth information about teachers' understanding of UDT principles among Saudi Arabian teachers who teach Deaf and Hard of Hearing $(\mathrm{DH} / \mathrm{H})$ students in general education schools in the area of Riyadh City. The theme coding and analytical interpretations of the data collected from both the interviews and the documents were used to make conclusions and recommendations regarding the overall Saudi Arabian teachers' understanding of UDT principles.

First, a semi-structured interview protocol was produced to meet the purpose of this qualitative study and the main target of the research questions (Creswell, 2012) and it was ready for use when the time came for the data collection stages of the study. Then, the researcher hired an expert who is specialized in Deaf and Hard of Hearing $(\mathrm{DH} / \mathrm{H})$ students' inclusion programs in both special and general education schools in the area of Riyadh City to conduct the interviews and record them. The resultant data recordings were transcribed in Arabic and then translated into English by the researcher himself, and this gave the researcher an opportunity to an early start of the analyses and interpretations. Finally, both the hired interviewer and the group of participants will be contacted and checked for their conformity and consistency of the researcher's interpretations and translations using the original responses of the participants to the interview questions.

\subsection{Procedures Overview}

- To seek permission for data collection, the researcher contacted the locations to which the participants belong and explain to the stakeholders and gatekeepers the purpose and significance of the study.

- To validate the interview protocols and make them more reliable, the researcher translated them to Arabic (the native language of the participants) and then they were sent to experts in the field of qualitative research design 
and research assessment for revision and feedback.

- Before conducting the interviews, each participant was asked to sign a consent form after briefing them about the purpose and the significance of this research.

- The data was collected, transcribed, and translated back into the English language, and then the transcriptions were theme-coded for analysis.

- The data will be destroyed as soon as the researcher publishes the results of his study.

- The researcher obtained approvals from officials, site administrators, gatekeepers, stakeholders, and individuals who are involved in the procedures of the study before administrating the instruments of the study for the collection of the data.

- The procedures included a form of informed consent and voluntary participation of the five Saudi teachers, who teach Deaf and Hard of Hearing $(\mathrm{DH} / \mathrm{H})$ students in general education schools in the area of Riyadh City.

\subsection{Data Collection ${ }^{1}$}

This study is aimed at identifying the Saudi Arabian teachers' understanding of UDT principle while being among individuals responsible for implementing inclusion and transition programs in KSA. The study examined how teachers' understanding of UDT principles might influence the implementation of UDT programs. The target sample is all Saudi school-teacher population, who teach Deaf and Hard of Hearing $(\mathrm{DH} / \mathrm{H})$ students in both special and general education schools of Saudi Arabian educational system. The accessible sample focuses on five participants. They are teachers who teach who teach Deaf and Hard of Hearing $(\mathrm{DH} / \mathrm{H})$ students in both special and general education schools in the area of Riyadh City.

The purpose of this qualitative study is to determine the barriers that might hurdle implementation of UDT in the future programs of transition education in KSA and to examine the influence that teacher understanding of UDT concepts might have over transitioned students' learning. According to Creswell (2012), qualitative research design is required when a researcher needs to present various perceptions of participants or cites to obtain an authentic view of the complexity of the real situation. Also, it is "It is typical in qualitative research to study a few individuals or a few cases. This minimal sample choice is because the overall ability of a researcher to provide an in-depth picture diminishes with the addition of each new individual or site" (Creswell, 2012: p. 209).

\footnotetext{
${ }^{1}$ The education system in KSA stipulates that all public schools and community education subject in curricula, technical supervision, and oversight by the Ministry of education in the country. Article 14 of the regulation school in KSA and provides: Article 14: the private schools and special education work in accordance with the State curriculum. As to the organizational manual regulation issued by the Ministry of education States that: Specialized programs in special education for students with disabilities in general education schools applied. There a lot of other laws that show that public schools and private schools or eligibility is subject to the same education system which imposed by the Ministry, like as stated in the rules governing the establishment of special education.
} 


\subsection{Population and Sample}

The accessible sample includes five Saudi Arabian teachers of students who are deaf or hard of hearing. The teachers, who are currently working in public school in and around the area of Riyadh the capital city of KSA, and who part of special education transition programs that are utilizing UDT principles in their implementations. The teachers who were graduated from Saudi teacher preparation programs about a decade ago and they have been qualified enough to teach $\mathrm{D} / \mathrm{HH}$ students in the national program of inclusion of students with disabilities. Therefore, all of them had had (according to a university plan to train the teacher to work with students with disabilities) a total number of 128 -hours of study and had completed all the required courses, which included methods and techniques of diagnosis, assessment/evaluation and teaching strategies for people with disability.

The sampling for the study was maximal variation sampling. According to Creswell (2012), "Maximal variation sampling is a purposeful sampling strategy in which the researcher samples cases or individuals that differ in some characteristic or trait" (pp. 208-209). Therefore, the sampling required that all the participants are teachers, who teach Deaf and Hard of Hearing $(\mathrm{DH} / \mathrm{H})$ students in both special and general education schools in the area of Riyadh City. The participants were contacted to obtain their initial agreement for participating in the interviews and for contributing documents (i.e. Individual Educational Plan used in their teaching) for the study. Before starting the interviews and using the documents in collecting the data for the study, permissions were taken from different individuals depending to their levels of participation (e.g. interviewees, gatekeepers, professionals in charge, etc.). The researcher obtained permission from the officials and administrators at the related school districts in the area of Riyadh City.

\subsection{Permissions Obtained}

To seek approval for data collection, the researcher contacted the locations to which the participants belong and explain to the stakeholders and gatekeepers the purpose and significance of the study. The stakeholders were briefed on the purpose of this research study, and they were told that the researcher needed their permission to contact and interview the participants on the locations and schools in which they work. The stakeholders and gatekeepers showed a good understanding, and they collaborated fully with both the researcher and the interviewer, and so the interviews were conducted in moral and formal status with every individual knowing what they were contributing to the study.

Also, the stakeholders were told about the interview protocols and how the researcher translated them to Arabic (the native language of the participants), and that each participant would be asked to sign the consent form that was designed to the purpose of the study. The research also disclosed to the stakeholders that the data would be collected, transcribed, and translated back into the 
English language, and then analyzed by the researcher himself and that no other person would have access to the data apart from the researcher.

When the researcher obtained approval from officials, site administrators, gatekeepers, stakeholders, and individuals who are involved in the procedures of the study, he contacted the hired interviewer and provided him with a package which contained the interview protocols and an instructions page. The page was showing how to brief the participants and inform them about their rights before administrating the instruments of the study for the collection of the data. The interviewer package included five forms of informed consent and voluntary participation of the five Saudi teachers, who teach Deaf and Hard of Hearing $(\mathrm{DH} / \mathrm{H})$ students in both special and general education schools in the area of Riyadh City.

\subsection{Ethical Considerations}

For this study to be ethical and conducted responsibly, the participants were given the right to decide the time and the length of their participation. Besides, the researcher applied for the permissions of the authorities and individuals to collect data and conduct the study in the proposed locations and time limits. Moreover, the researcher has made sure that the participants know their rights and a consent form was administrated before the data collection steps.

The participants were told that the study is going to be published and their names will remain anonymous, as the researcher will use pseudo names instead of the real ones to conceal the identity and information of the sample participants. The participants have known that participation in the study is voluntary and all the participants were given a consent form to read and sign before taking the interviews. The consent form included an explanation of the purpose of the study and that the participants are free to withdraw from the study at any time without being held responsible for any consequences. The participants were also told about the procedures of the study and that permission of accessing the study cities have been obtained from the educational officials. Also, the participants were told by the hired interviewer that he was only hired to conduct the interviews and that the interviews were recorded to enable the researcher to follow the analysis procedures and discussion of results.

\subsection{Instrumentation}

The research design of this study is qualitative and for triangulation two instruments were used namely a semi-structured interview and analysis of teaching documents. According to Golafshani (2003), triangulation is a qualitative technique, which researchers need to ensure that the validity and reliability of research findings are improved. First, the study utilized a semi-structured interview protocol, which was designed for the purpose and the research questions of the study. The interview protocol includes 43 items, statements, open-ended 
questions, invitations, and prompts. They are used to answer the questions about Saudi teachers, who teach Deaf and Hard of Hearing (DH/H) students in both special and general education schools in the area of Riyadh City regarding their understanding of UDT principles. Finally, this interview protocol was translated from English to Arabic and modified to meet the contextual differences of the Saudi educational setting of this study.

The document analysis included investigating three documents, which the participants contributed to this study. One document was a national teaching plan, which is used as a guidance reference to inform special education teachers in KSA. The other two documents were a math lesson plan and an Arabic Language class lesson plan, which the participants used in their classes. The aim was to examine accordance of such documents with the international standards of UDT principles. Both the instruments of the study were administrated timely and according to qualitative procedures and were adequate sources of data during the data collection stages of the study.

\section{Data Analysis}

First, the researcher administrated both instruments of the study (i.e. interviews and document analysis) during an inclusion program. Then, the analysis included interpreting data collected about teachers' understanding of UDT principles among Saudi Arabian teachers who teach Deaf and Hard of Hearing $(\mathrm{DH} / \mathrm{H})$ students in both special and general education schools in the area of Riyadh City. The analysis also included the theme coding and analytical interpretations of the data collected from both the interviews and the documents to be used to make conclusions and recommendations regarding the overall Saudi Arabian teachers' understanding of UDT principles.

The analysis involved translation of the semi-structured interview back into English so that the translated data would be used to answer the research questions. The resultant data recordings were transcribed in Arabic and then translated into English by the researcher himself, and this gave the researcher an opportunity to an early start of the analyses and interpretations. Then, the researcher contacted the hired interviewer to check the conformity of the translations. Finally, both the hired interviewer and the group of participants were contacted and checked for their conformity and consistency of the researcher's interpretations and translations using the original responses of the participants to the interview questions.

\section{Findings}

The purpose of this study is to examine whether the concepts of UDT are understood and successfully incorporated into the activities of teachers, who teach Deaf and Hard of Hearing $(\mathrm{DH} / \mathrm{H})$ students in general education schools of Saudi Arabian educational system. Therefore, the following questions were based on the relationship between teachers' understanding of the seven prin- 
ciples of UDT and the barriers that might occur when UDT as an instructional design framework is implemented in the schools of KSA:

\section{1) Teachers don't know about UDT:}

Although the participants did not know much about the UDT principles, it seems that they are aware of the importance of the existence of a conscious team aware of its functions is very important indeed. But all of them emphasized that need for regulations and rules that govern the work and define the tasks of each member clearly and accurately. Yousef said that: "Very important, and there should be regulations set to run on the work of the team." Saeed said: "Having a team is undoubtedly important and there should be regulations set to ensure its success." As an answer to a question that asked: "How would you describe your knowledge of the UDT?", The participants said that they have no idea and one of them (Saeed) commented: "My knowledge might be so limited since I have not had any information on the part of supervisors." The participants indicated that they completely lack the scientific knowledge and the field experience about designs such as UDT. Ali commented that he "Actually, I have no prior knowledge of universal design for transition" (Interview Question 10).

According to the participants' responses, there are no transition programs implemented in their schools as they are part of the whole educational system which does not include such programs. This scenario indicates that their experiences with UDT principles remain a matter of personal attempt and personal educational opportunity, especially when the educational authorities do not have any training programs regarding the development of knowledge experience for the teachers. Schools do not have any transition programs, and so the teachers' linkage to UDT principles is awaiting the educational authorities to take measure toward including such UDT programs in their curricula, which would make the teachers more knowledgeable as they would need it in their daily school practice. Saud says: "I do not have any experience except for the counseling programs planned by the guidance counselor, and all we do is just implementing these programs" (interview question 12). On the other hand, Yousef, who managed to ask the interviewer and get an idea about UDT as a design framework for learning, commented that: "If the universal design for transition is concerned about students' employment, it would be perfect" (interview question 12).

When the participants were asked to share all that they had known about the advantages of the universal design for transition, they expressed their inability to share anything because they originally did not know what it means, and so talking about its advantage is out of the question.

Many times the participants had to emphasize their lack of knowledge about UDT principles and programs. They kept repeating expressions like; "As previously mentioned, I don't know what universal design for transition means." (Abdullah); "As far as I know, KSA does not have any form of universal design." (Yousef); "I don't have any information or first-hand experience with this design." (Abdullah) "To my knowledge, it is almost negligible at the level of Arab 
countries." (Saeed); "I have no experience with those kinds of programs." (Ali); "I have no clue about this design." (Saud); "I don't have any experience with those kinds of designs." (Youse); and "I don't have any knowledge of those kinds of programs" (Saeed).

\section{2) Barriers of implementing UDT in Saudi schools:}

The participants said that they cannot say whether to adopt the UDT concepts or not since they do not know much about it. They explained that because they are not informed about it and that they think having to adopt something just because it is a requirement of the ministry of education might cause difficulties and challenges to its implementation. Another issue that concerned the participants has been the appropriateness of their schools or implementing UDT programs in the future. According to Ali, "Unfortunately, the school is not ready yet to implement these kinds of strategies." They said that their schools are in need of physical modifications as well as human and cultural requirements for implementing such programs as UDT principles. For example, the participants emphasized that their schools need to be equipped with technology before the implementation of these programs as these programs rely on technology.

When the participants were asked to share their suggestions and ideas for improving their students' future transition, they all indicated the vitality of "simulation of established programs, which proved successful." (Ali); "holding training courses for specialists in the field." (Abdallah); "training courses and workshops should be run to raise awareness." (Yousef); "seminars and introductory lectures are the best vehicles to raise awareness" (Saeed).

Moreover, some of the participants expressed their concerns and worries saying that the implementation of such programs of disability education might be introduced without the establishment of supporting environment and well-prepared personnel. For example, Saeed commented that he is "afraid that the application if there is any, will be undergone randomly without creating the spatial and human environment commensurate with it."

Despite participants' awareness that technology is a vital tool for helping people with disabilities acquire academic skills that can support their weakness, the responses to the interview questions showed that their technological knowledge "is insufficient" due to lack of experience. Their responses were a lot similar in that they all focused on the technology is a new advancement that needs learning and experience, which explains their worries toward implementing such an advanced program as UDT in the Saudi educational system at the moment. Also, they blamed the educational authorities for their lack of technological knowledge commenting that even their limited experience of technology has resulted from their efforts rather than training policies of their institutions or educational districts. To the participants, integration of UDT in the Saudi school curricula is impossible at the moment, and so are no indications of integration soon. Saud also shred his pessimism regarding the integration of UDT in the Saudi educational system saying that he is pessimistic and that: "the reason for 
this is the lack of any skills or knowledge from the part of teachers regarding the use of this design in the curriculum" (Interview Question 14)

Among the obstacles that the participants mentioned were lack of knowledge relevant integrating UDT programs in the education system, bureaucracy, shortage of sufficient knowledge, the inability to transfer experiences by teaching staff members, unqualified leadership. Also, another barrier some participants warned against was lack of technology infrastructure. However, the participants believe that once training courses are provided, teachers will be able to gain awareness of the significance of these programs. According to 'Abdullah,' who has been a special education teacher for about years, "Among the obstacles associated to using universal design for transition are the lack of resources and knowledge relevant to this sort of strategy" (Interview Question 20). Saud says that theoretically one can talk about teamwork, but in reality, it does not exist in the teaching practice of the Saudi teachers, "only on paper." Saeed said that "The application has not been implemented to date and there is no room for mentioning any difficulties or challenges that could limit the success of the program" (Interview Question 27).

The most striking result of this study is that the participants commented their pessimism about implementing UDT in the future. It is clear they are blaming it on their supervisors and their institutes who are not contributing any preparation and training to implementation of such programs.

3) Teachers' understanding of the principles affects UDL programs at schools of general education and special education:

According to Ali, "It's hard to say in cases like this if it is important or not since I do not know the advantages of these kinds of programs. I cannot assess them for not being existing in schools" (Interview Question 18). The participants refused to talk about the advantages of UDT programs either because their schools do not have such programs, or because they do not know anything about them, as they "have no previous knowledge with these kinds of designs" (Saeed) IQ 18. The participants emphasized the importance of having regulations for organizing teamwork to make it successful and beneficial for any future programs. According to Saeed, the existence of a conscious team aware of its functions is very important indeed. This functionality can only be achieved, however, through setting regulations and rules that govern the work and define the tasks of each member clearly and accurately" (Interview Question 26). Although all the participants have experience of teaching with $\mathrm{D} / \mathrm{HH}$ students, they were not ready to tackle difficulties and challenges regarding implementation of UDT because they think it is early to talk about challenges when the program itself does not exist. However, one of them said: "Despite the lack of implementation and the absence of any difficulties related to this type, we usually overcome the difficulties that face us through a complete withdrawal from the confrontation. Its impact is clear that it will be a stumbling block to progress" (Interview Question 29). 
The participants repeatedly reported that their technical knowledge is limited and it is due to lack of training and development programs on the part of the ministry of education. They all emphasized the insufficient experience of using technology even though according to (Ali) one of the participants, "Technology is a vital tool for helping people with disabilities acquire academic skills and support their weakness" (Interview Question 5).

\section{Discussion}

Moreover, some of the participants expressed their concerns and worries saying that the implementation of such programs of disability education might be introduced without the establishment of supporting environment and well-prepared personnel. For example, Saeed commented that he is "afraid that the application if there is any, will be undergone randomly without creating the spatial and human environment commensurate with it." A quick comparison of the findings to the literature has revealed why teachers of students who are $\mathrm{D} / \mathrm{HH}$ are concerned about the future implementation of UDT programs in KSA.

The participants are teachers who were graduated from Saudi teacher preparation programs some time ago, and they have been qualified enough to teach $\mathrm{D} / \mathrm{HH}$ students in the national program of inclusion of students with disabilities. Therefore, all of them had had (according to a university plan to train the teacher to work with students with disabilities.) a total number of 128 hours of study and had completed all the required courses, which included methods and techniques of diagnosis, assessment/evaluation and teaching strategies for people with disability. According to Saeed, "the university plan focused on the characteristics of people with disabilities, the methods of diagnosis and, teaching." Therefore, the participants' background is what has shaped them so that they care about being in such programs to support students with disabilities. In other words, what matters to them is to be in the appropriate place and the best program to teach the student with disabilities population. Some of their comments indicated that the inclusion program in which they are working right now is not only important but it also effectively serves the needs of people with disabilities. Their official working hours are typically from 7:00 am to 1:00 pm and sometimes they have to stay at work throughout the school day depending on the requirements of their teaching and inclusion tasks.

\section{Limitations and Future Research}

One limitation was the fact that the researcher had to hire someone to conduct the interviews. Although the hired interviewer was qualified and experienced in the context of the study, he lacked the atmosphere that a researcher gains from writing the background of the study and the literature review, which in fact can guide an interviewer into seeking more details during the interview moments. For example, when one of the participants (Ali) said: "Unfortunately, the school is not ready yet to implement these kinds of strategies." The interviewer could 
have asked him to elaborate more on this point, but he did not, perhaps because he did want to distract the participants from the interview course. In this way, the researcher feels that many details have gone unexplained due to the hired interviewer's lack of a real view of the literature review about the UDT principles although he was well informed about the research problem, the purpose of the study, and the research questions.

Another limitation was that the sample did not include female participants. Although gender is an essential factor in collecting data form teachers of special education as students with disabilities are not only males and teachers of $\mathrm{D} / \mathrm{HH}$ students are of both sexes. Also, in Saudi Arabian educational system is in the use of separate sex education, and female teachers only teach so female students. This fact makes it necessary to study both male and female teachers to collect data about both cases. Therefore, the findings of this study cannot be generalized to the whole Saudi teacher population unless the female teachers are also interviewed, and their responses analyzed to get a full view of the situation. The researcher recommends that future studies should focus on research that includes female teachers in the sampling procedures.

The participants were asked to share their suggestion regarding more interaction with other colleagues at work and more teamwork to make the inclusion program successful. Their responses focused on training and development for the teachers, e.g. training courses, seminars, courses, and workshops, for the teachers to help them share their experiences with each other.

Although all the participants hold that the inclusion program is an appropriate program for students with disabilities, they indicated that there is little or no collaboration with other teachers in the program. They blamed such defect on lack of communication through technology among the teachers. When they were asked to tell how they got to know other teachers in the program, the respondents said that the either met them at the university during their teacher preparation programs or they met them recently in the same workplace. For example, Saud noted that: "Basically, I have met many colleagues in the workplace. However, some of them I have known since I was a student at university" (Interview Question 25).

Although all the participants were positive about assistive technology and its significant role in the development of students' academic skills, they still think that their work environment is not helping them teach with technology. Apparently, they commented that the environment is neither supportive nor motivational to induce teachers to use technology in their teaching practice. Two of the participants (i.e. 40\%) said that they would not stay to teach in the same school, but they did not explain why. On the other hand, $60 \%$ reported that they would keep on teaching in the same school because it is the right place to teach students with and gain more experience in the field of special education.

\section{References}

Agency for Healthcare Research and Quality (2013). Mixed Methods: Integrating Quan- 
titative and Qualitative Data Collection and Analysis While Studying Patient-Centered Medical Home Models.

https://pcmh.ahrq.gov/sites/default/files/attachments/MixedMethods_032513comp.pdf

Aldabas, R. (2015). Special Education in Saudi Arabia: History and Areas of Reform. Creative Education, 6, 1158-1167. https://doi.org/10.4236/ce.2015.611114

Al-Mousa, N. A. (2008). Special Education in the Kingdom of Saudi Arabia: From Separation to Integration. Dubai: Dar Al-Kalam.

Al-Musa, N. (1999). Development of Special Education in the Ministry of Education in the Kingdom of Saudi Arabia. Riyadh: King Fahad Library.

Al-Muscat, A. (1984). Effort of Saudi Arabia in the Field of Educating the Deaf.

Alnahdi, G. (2014). Assistive Technology in Special Education and the Universal Design for Learning. Turkish Online Journal of Educational Technology, 13, 18-23.

Al-Rayes, T. S., \& Al-Zahrani, M. (2015). Teachers and Specialists Attitudes toward Implementing Transitional Programs for Deaf Students, and the Difficulties They Face in the Implementation in Al-Amal Institutes in Riyadh. Journal of Educational and Psychological Studies, 9, 230-247. https://doi.org/10.24200/jeps.vol9iss2pp230-247

Alzahrani, M. (2012). The Actual Status of Implementing Transitional Programs for Deaf Students at the Secondary Level, and the Difficulties of Its Implementation, from the Point of View of Teachers and Specialists in Al-Amal Institutes in Riyadh. Riyadh: King Saud University.

Al-Zawei, A., Serenelli, F., \& Lundqvist, K. (2016). Universal Design for Learning (UDL): A Content Analysis of Peer-Reviewed Journal Papers from 2012 to 2015. Journal of the Scholarship of Teaching and Learning, 16, 39-56. https://doi.org/10.14434/josotl.v16i3.19295

Ankeny, E. M., Wilkins, J., \& Spain, J. (2009). Mothers' Experiences of Transition Planning for Their Children with Disabilities. Teaching Exceptional Children, 41, 28-36. https://doi.org/10.1177/004005990904100604

Antia, S. D. (1999). The Roles of Special Educators and Classroom Teachers in an Inclusive School. Journal of Deaf Studies and Deaf Education, 4, 203-214.

http://jdsde.oxfordjournals.org/content/4/3/203.full.pdf + html?sid=d172c216-676b-44d 7-8d76-fd473a2c572e

Aslaksen, F., Bergh, S., Bringa, O., \& Heggem, E. (1997). Universal Design: Planning and Design for All. The Norwegian State Council on Disability. http://digitalcommons.ilr.cornell.edu/cgi/viewcontent.cgi?article=1329\&context=gladn etcollect

Aud, S., Wilkinson-Flicker, S., Kristapovich, P., Rathbun, A., Wang, X., \& Zhang, J. (2013). Condition of Education 2013 (NCES 2013-037). Washington, DC: U.S. Department of Education, National Center for Education Statistics.

Avramidis, E., \& Kalyva, E. (2017). The Influence of Teaching Experience and Professional Development on Greek Teachers' Attitudes towards Inclusion. European Journal of Special Needs Education, 22, 367-389. https://doi.org/10.1080/08856250701649989

Best, K., Scott, L., \& Thoma, C. (2015). Starting with the End in Mind: Inclusive Education Designed to Prepare Students for Life. In E. Brown, R. Craven, \& G. McLean (Eds.), International Advances in Education: Global; Initiatives for Equity and Social Justice: Volume 9, Inclusive Education for Students with Intellectual Disabilities (pp. 45-72). Charlotte, NC: Information Age Press.

Bin Battal, Z. (2016). Special Education in Saudi Arabia. International Journal of Technology and Inclusive Education, 5, 880-886. 
Cannon, J., Guardino, C., Antia, S., \& Luckner, J. (2016). Single-Case Design Research: Building the Evidence Base in the Field of Education of Deaf and Hard of Hearing Students. American Annals of the Deaf, 160, 440-452.

https://doi.org/10.1353/aad.2016.0007

Carrington, S., Deppeler, J., \& Moss, J. (2010). Cultivating Teachers' Beliefs, Knowledge and Skills for Leading Change in Schools. Australian Journal of Teacher Education, 35, 1-13. https://doi.org/10.14221/ajte.2010v35n1.1

Cawthon, S., \& Caemmerer, J., Pepnet 2 Research and Evidence Synthesis Team (2014). Parents' Perspectives on the Transition and Postsecondary Outcomes for Their Children Who Are Deaf or Hard of Hearing. American Annals of the Deaf, 159, 7-21. https://doi.org/10.1353/aad.2014.0013

Cook, B. G. (2004). Inclusive Teachers' Attitudes toward Their Students with Disabilities: A Replication and Extension. The Elementary School Journal, 104, 307-320. http://www.jstor.org.lynx.lib.usm.edu/stable/pdfplus/10.2307/3202944.pdf?acceptTC=true https://doi.org/10.1086/499755

Creswell, J. W. (2012). Educational Research: Planning, Conducting, and Evaluating Quantitative and Qualitative Research (4th ed.). Upper Saddle River, NJ: Merrill Prentice Hall.

Eriks-Brophy, A., \& Whittingham, J. (2013). Teachers' Perceptions of the Inclusion of Children with Hearing Loss in General Education Settings. American Annals of the Deaf, 158, 63-97. https://doi.org/10.1353/aad.2013.0009

http://muse.jhu.edu.lynx.lib.usm.edu/journals/american_annals_of_the_deaf/v158/

Evans, C., Williams, J., King, L., \& Metcalf, D. (2010). Modeling Guided Instruction and Application of UDL in a Rural Special Education Teacher Preparation. Rural Special Education Quarterly, 29, 41-48. https://doi.org/10.1177/875687051002900409

Fowler, C. H., Test, D. W., Cease-Cook, J., Toms, O., Bartholomew, A., \& Scroggins, L. S. (2014). Policy Implications of High School Reform on College and Career Readiness of Youth with Disabilities. Journal of Disability Policy Studies, 25, 19-29. https://doi.org/10.1177/1044207313518072

Gallaudet Research Institute (2013). Regional and National Summary Report of Data from the 2011-2012 Annual Survey of Deaf and Hard of Hearing Children and Youth. Washington DC: Gallaudet Research Institute.

Golafshani, N. (2003). Understanding Reliability and Validity in Qualitative Research. The Qualitative Report, 8, 597-606.

Hadidi, M. S., \& Al Khateeb, J. M. (2015). Special Education in Arab Countries: Current Challenges. International Journal of Disability, Development and Education, 62, 578-530. https://doi.org/10.1080/1034912X.2015.1049127

Hartmann, E., \& Weismer, P. (2016). Technology Implementation and Curriculum Engagement for Children and Youth Who Are Deaf-Blind. American Annals of the Deaf, 161, 462-473. https://doi.org/10.1353/aad.2016.0038

Kim, W. H., \& Lee, J. (2016). The Effect of Accommodation on Academic Performance of College Students with Disabilities. Rehabilitation Counseling Bulletin, 60, 40-50. https://doi.org/10.1177/0034355215605259

Luckner, J., \& Sebald, A. (2013). Promoting Self-Determination of Students Who Are Deaf or Hard of Hearing. American Journal Annal of the Deaf, 158, 377-386. https://doi.org/10.1353/aad.2013.0024

Luft, P., \& Huff, K. (2011). How Prepared Are Transition-Age Deaf and Hard of Hearing Students for Adult Living? Results of the Transition Competence Battery. American Annals of the Deaf, 155, 569-579. https://doi.org/10.1353/aad.2011.0000 
Mapolisa, T., \& Tshabalala, T. (2013). The Impact of Inclusion of Children with Hearing Impairment into Regular Schools: A Case Study of Dakamela Primary School in Zimbabwe. International Journal of Asian Social Science, 3, 1500-1510.

Mayer, R. (2008). Applying the Science of Learning: Evidence-Based Principles for the Design of Multimedia Instruction. American Psychologist, 63, 760-769. https://doi.org/10.1037/0003-066X.63.8.760

National Center on Universal Design for Learning (2010). Elementary and Secondary Education (ESEA) Reauthorization and Universal Design for Learning. http://www.udlcenter.org/sites/udlcenter.org/files/UDL.ESEA_Recs_.Dec2010.pdf

Rose, D., Harbour, W., Johnston, C., Daley, S., \& Abarbanell, L. (2006). Universal Design for Learning in Postsecondary Education: Reflections on Principles and Their Application. Journal of Postsecondary Education and Disability, 19, 135-151.

Scott, L., Saddler, S., Thoma, C., Bartholomew, C., Virginia, N., \& Tamura, R. (2011). Universal Design for Transition: A Single Subject Research Study on the Impact of UDT on Student Achievement, Engagement and Interest. I-Manager's Journal on Educational Psychology, 4, 21-32.

Shaira, M. (2013). Effects of Inclusion on Language Development in Hearing-Impaired Students in Jeddah Schools: Perspectives of Teachers and Parents. Life Science Journal, 10, 2374-2383.

Stolz, S. (2010). Disability Trajectories: Disabled Youths' Identity Development, Negotiation of Experience and Expectation, and Sense of Agency during Transition. Doctoral Dissertation, San Diego, CA: University of California. https://escholarship.org/content/qt7zg9w5ht/qt7zg9w5ht.pdf

Thoma, C. A., Cain, I., Wojcik, A. J., Best, K., \& Scott, L. A. (2016). Universal Design for Transition for Students on the Autism Spectrum. Autism Spectrum Disorders: Identification, Education, and Treatment (p. 285, 4th ed.). New York, NY: Roultledge.

Thoma, C., Bartholomew, C., \& Scott, L. (2009). Universal Design for Transition: Roadmap for Planning and Instruction. Baltimore: Paul H. Brookes.

Vermeulen, J., Denessen, E., \& Knoors, H. (2012). Mainstream Teachers about Including Deaf or Hard of Hearing Students. Teaching and Teacher Education, 28, 174-181. https://doi.org/10.1016/j.tate.2011.09.007

Wehmeyer, M. (2006). Universal Design for Learning, Access to the General Education Curriculum and Students with Mild Mental Retardation. Exceptionality, 14, 225-235. https://doi.org/10.1207/s15327035ex1404_4 